\title{
Long-Term Beneficial Effect of Infarct-Related Artery Patency in Acute Anterior Myocardial Infarction in Patients With Poor Myocardial Viability in the Region-at-Risk
}

\author{
Daiju Fukuda, MD; Minoru Yoshiyama, MD; Kenei Shimada, MD; \\ Takahiko Kawarabayashi, MD*; Atsushi Tanaka, MD*; Shoichi Ehara, MD; \\ Yasuhiro Nakamura, MD; Kaname Akioka, MD; \\ Kazuhide Takeuchi, MD; Junichi Yoshikawa, MD
}

\begin{abstract}
Background Several studies have demonstrated the benefit of the patency of infarct-related artery (IRA) in acute myocardial infarction (AMI). However those studies have not been concerned with myocardial viability in the region-at-risk. In the present study the effect of the patency of IRA was investigated in the setting of anterior AMI with poor viable myocardium in the risk region.

Methods and Results From 1993 to 1996 patients with a first time anterior AMI and poor viable myocardium in the region-at-risk at 1 month after onset were identified and enrolled. Patients with a totally occluded IRA were included in the Non-Open group $(n=44)$, and patients with a reperfused IRA were included in the Open group $(n=49)$. At 5 years after onset, left ventricular function was better preserved in the Open group than in the Non-Open group $(\mathrm{p}<0.05)$. Kaplan-Meier survival curves for cardiac mortality and event-free survival curves revealed poor prognoses in the Non-Open group over a 5 -year period ( $\mathrm{p}<0.05$, respectively). The advantages of a patent IRA were further seen in health-related quality-of-life outcomes $(\mathrm{p}<0.05)$.

Conclusions Even in patients with poor myocardial viability after an anterior AMI, the patency of the IRA is strongly associated with improved long-term survival, independent of residual myocardium viability. (Circ $J$ 2004; 68: 1110-1116)
\end{abstract}

Key Words: Myocardial infarction; Prognosis; Remodeling; Reperfusion

$\mathbf{R}$ eperfusion therapy in the first hours following the onset of acute myocardial infarction (AMI), whether by thrombolytic therapy ${ }^{1,2}$ or percutaneous coronary intervention (PCI), has clearly demonstrated benefits on mortality and ventricular function?,4 The improvement is thought to be primarily related to a reduction in infarct size.

However, several studies have suggested that even if patency of the infarct-related artery (IRA) is achieved late (ie, too late to prevent myocardial necrosis), the short- and long-term patient outcomes are still better than those of patients whose IRA remains totally-occluded 5,6 Late PCI has recently been shown to be associated with a high success rates, low complication rates, and a low incidence of reocclusion? Bauters et al reported in 1999 that late reocclusion after successful coronary angioplasty for an IRA was a powerful predictor of long-term mortality, but in the stent era, the greater likelihood that the IRA can be kept patent has, to some extent, altered the clinical landscape.

(Received May 24, 2004; revised manuscript received September 10, 2004; accepted September 29, 2004)

Department of Internal Medicine and Cardiology, Graduate School of Medicine, Osaka City University Medical School, Osaka and *The Baba Memorial Hospital, Sakai, Japan

Mailing address: Daiju Fukuda, MD, Department of Internal Medicine and Cardiology Graduate School of Medicine, Osaka City University Medical School, 1-4-3 Asahimachi, Abenoku, Osaka 545-8585,

Japan. E-mail: daiju@qg7.so-net.ne.jp
The previous studies of late reperfusion, IRA patency and potential long-term benefits, that is, the 'open vessel theory', have not been concerned with the viability of the at-risk region of the IRA, meaning that the beneficial effect may simply be attributable to the recovery of stunned or hibernating myocardium. The beneficial effect of IRA patency for patients with poor viable myocardium in the infarction area has not been well investigated and studies are necessary to determine the beneficial effects of IRA patency more fully and accurately.

In the present study, we evaluated the efficacy of the 'open vessel theory' by looking at the incidence of adverse cardiac events, left ventricular (LV) function, and healthrelated quality of life (HRQOL) in anterior AMI patients with similar backgrounds who were admitted to 2 hospitals with different primary strategies for AMI.

\section{Methods}

\section{Study Design}

This study was a retrospective analysis of 2 similar patient populations admitted to either The Baba Memorial Hospital or The Osaka City University Hospital. These 2 institutions had different primary strategies, and this study was designed to assess the effect of the patency of the IRA in patients with poor myocardial viability.

All patients in the study were admitted to one of these institutions between 1993 and 1996 for a first-time anterior 
AMI, arrived at the coronary care unit $>12 \mathrm{~h}$ after onset, and prior to discharge underwent symptom-limited exercise ${ }^{201} \mathrm{Tl}$ myocardial single photon emission computed tomography (SPECT) scintigraphy with re-injection that revealed very poor viability in the region-at-risk. Our research took place from January 2001 to May 2001 during which period all patients with whom we were able to make contact (as well as those patients whose deaths could be confirmed by their families) were eligible for inclusion. We excluded from the study patients who suffered mortality within 1 year of onset of symptoms, in order better to reflect the beneficial effects of the IRA being open, irrespective of the patient's condition in the acute phase. Study patients were assigned to either a Non-Open group or an Open group on the following basis.

The Baba Memorial Hospital, on the basis of the report of Hirayama et al about the efficacy of late reperfusion? had a strategy of reperfusing patients even $>12 \mathrm{~h}$ after the onset of symptoms. Patients treated at this hospital and who met the following criteria made up the Open Group: (a) successful PCI for the left anterior descending artery (LAD) at the time of admission; (b) repeat coronary angiography $(\mathrm{CAG})$ after 1 month of cardiac rehabilitation revealed patency of the LAD; and (c) further CAG at 6 months after onset also showed a patent LAD. In this population of 150 patients, 3 died within 1 year of onset, 9 could not be contacted, and 89 were unavailable for repeat CAG and ${ }^{201} \mathrm{Tl}$ myocardial SPECT evaluation, leaving a final total of 49 .

The Osaka City University Hospital had a policy of no PCI for patients $>12 \mathrm{~h}$ after onset unless they presented with fresh episodes of angina pectoris. Patients treated at this hospital and who met the following criteria made up the Non-Open Group: (a) no PCI in the acute phase; (b) CAG after 1 month of cardiac rehabilitation revealed total occlusion of the LAD; and (c) no PCI performed in the occluded artery. In this population of 175 patients, there were 8 mortalities within 12 months, 17 patients could not be contacted, and 106 were unavailable for repeat CAG and ${ }^{201} \mathrm{Tl}$ myocardial SPECT observation, leaving a total of 44 subjects in the Non-Open group.

The following were held to be reasons for exclusion from the study. (a) a spontaneously reperfused IRA at the time of first CAG; (b) previous coronary bypass surgery; (c) left main coronary artery disease; (d) bypass surgery during the follow-up period; (e) severe valvular disease; or (f) some other life-threatening disease.

The study protocol was approved by the Ethics Committees of the Osaka City University Hospital and the Baba Memorial Hospital. We obtained written informed consent from all patients.

\section{Interventional Procedure (Open Group)}

AMI was defined as follows: typical chest pain $>30 \mathrm{~min}$ duration; creatine kinase $(\mathrm{CK})>150 \mathrm{IU}$; and ECG evidence of AMI (ST elevation $>1 \mathrm{~mm}$ on contiguous leads or the subendocardial pattern). Following the diagnosis of AMI, PCI was performed according to standard techniques in patients in the Open group only at the time of admission, after administration of heparin (10,000 U). Angiographic success was defined as Thrombolysis in Myocardial Infarction grade 2 or 3 flow and $<50 \%$ diameter stenosis after intervention. Balloon angioplasty was accompanied by administration of aspirin, and stent implantation by ticlopidine.

\section{Cardiac Catheterization Prior-to-Discharge}

Following intravenous administration of heparin (5,000 U), CAG and left ventriculography (LVG) were performed using standard techniques for all patients in both groups. CAG used multiple views to visualize the IRA, whereas LVG used a 30-degree right anterior oblique projection. LV ejection fraction (LVEF), end-diastolicvolume index (LVEDVI), and end-systolic-volume index (LVESVI) were calculated using the area-length method ${ }^{10}$ to evaluate $\mathrm{LV}$ function.

\section{Assessment of Myocardial Viability}

In order to evaluate residual myocardial viability, all patients underwent symptom-limited exercise ${ }^{201} \mathrm{Tl}$ myocardial SPECT with re-injection of ${ }^{201} \mathrm{Tl}$ at rest immediately after stress-redistribution imaging at 1 month after the onset of AMI!1,12 To evaluate myocardial viability in the risk territory, all SPECT images, including the re-injection image, were evaluated by 2 experienced observers who reached a consensus in their results. Poor viable myocardium in the region of the LAD was defined as severely reduced or absent uptake in the anterior, septal or apical region of the LV. Semi-quantitative assessment of myocardial viability used the 'Imaging Guidelines For Nuclear Cardiology Procedures'13 The LV was divided into 17 segments, and each segment was scored: 0, normal perfusion; 1 , mild reduction; 2 , moderated reduction; 3 , severe reduction; 4, absent reduction. The averaged value of 7 segments of those are thought to be perfused by LAD was calculated.

\section{Follow-up Angiography}

Follow-up CAG was performed 6 months after onset in all patients in the Open group to confirm IRA patency and to assess restenosis. Restenosis was defined, using quantitative $\mathrm{CAG}$, as $>50 \%$ luminal narrowing in the coronary artery segment that underwent PCI.

\section{Long-Term Follow-up}

As the long-term follow-up data, the incidence of death and cardiac events were investigated from a systematic review of the 2 hospitals' outpatient charts. Cardiac death was defined as death from congestive heart failure (CHF) or recurrence of myocardial infarction (MI) and sudden death. Rehospitalization because of CHF or recurrence of $\mathrm{MI}$ and cardiac death was considered a cardiac event. Information about patients referred to other hospitals was obtained by telephone interviews with the patients or their general practitioners, as well as with the hospitals they attended. Information about deceased patients was obtained from family members, their general practitioners, and the hospitals to which they had been admitted.

\section{Measurement of LV Function in the Chronic Phase}

During the research period, LV function was assessed by 2-dimensional (D) echocardiography, done in the standard manner. LV end-diastolic volume (LVEDV) and end-systolic-volume (LVESV) were measured using a Simpson rule algorithm, and the LVEDVI and LVESVI were calculated. LVEF was calculated according to the formula $(\mathrm{EDV}-\mathrm{ESV}) / \mathrm{EDV} \times 100 \%$. For the diastolic function of the LV, LV inflow velocities were measured by pulsed Doppler echocardiography. Early (E) and late (A) filling velocities and the deceleration time of early filling (Dct) were measured from direct tracing of the instantaneous time-velocity curves. The ratio of early-to-late filling 
Table 1 Baseline Patient Characteristics

\begin{tabular}{|c|c|c|c|}
\hline & $\begin{array}{c}\text { Non-Open } \\
(n=44)\end{array}$ & $\begin{array}{c}\text { Open } \\
(n=49)\end{array}$ & $p$ value \\
\hline Age (years) & $59.4 \pm 9.7$ & $59.7 \pm 10.2$ & $N S$ \\
\hline Male & $37(84)$ & $43(88)$ & $N S$ \\
\hline \multicolumn{4}{|l|}{ Risk factors } \\
\hline Hypertension & $15(34)$ & $23(47)$ & $N S$ \\
\hline Hypercholesterolemia $(>220 \mathrm{mg} / \mathrm{dl})$ & $15(34)$ & $21(43)$ & $N S$ \\
\hline Diabetes mellitus & $14(32)$ & $11(22)$ & NS \\
\hline Smoking & $29(66)$ & $27(55)$ & $N S$ \\
\hline Family history & $8(18)$ & $9(20)$ & $N S$ \\
\hline Obesity (body mass index $>25$ ) & $6(14)$ & $10(20)$ & $N S$ \\
\hline Pre MI-AP & $29(66)$ & $26(53)$ & $N S$ \\
\hline Cardiogenic shock & $7(16)$ & $3(6)$ & $N S$ \\
\hline Forrester class & & & $N S$ \\
\hline 1 & $28(64)$ & $27(54)$ & \\
\hline 2 & $10(23)$ & $9(18)$ & \\
\hline 3 & $5(11)$ & $9(18)$ & \\
\hline 4 & $1(2)$ & $4(8)$ & \\
\hline Peak $C K(I U / L)$ & $3,845 \pm 2,136$ & $4,587 \pm 2,614$ & $N S$ \\
\hline \multicolumn{4}{|l|}{ Intervention procedure } \\
\hline Thrombolytic therapy & - & $28(57)$ & - \\
\hline Plain old balloon angioplasty & - & $48(98)$ & - \\
\hline Stent implantation & - & $9(18)$ & - \\
\hline No. of diseased vessels & & & $N S$ \\
\hline 1 & $36(82)$ & $39(80)$ & \\
\hline 2 & $6(14)$ & $7(14)$ & \\
\hline 3 & $2(4)$ & $3(6)$ & \\
\hline \multicolumn{4}{|l|}{$L V G$ data } \\
\hline$E F(\%)$ & $43.7 \pm 10.1$ & $50.2 \pm 9.4$ & $N S$ \\
\hline $\operatorname{EDVI}\left(\mathrm{ml} / \mathrm{m}^{2}\right)$ & $102.5 \pm 21.4$ & $96.3 \pm 17.4$ & $N S$ \\
\hline $\operatorname{ESVI}\left(\mathrm{ml} / \mathrm{m}^{2}\right)$ & $61.7 \pm 18.0$ & $50.0 \pm 10.8$ & $N S$ \\
\hline
\end{tabular}

Data are mean value $\pm S D$ or number $(\%)$.

$M I$, myocardial infarction; $A P$, angina pectoris; $C K$, creatinine kinase; LVG, left ventriculography; EF, ejection fraction; EDVI, enddiastolic volume index; ESVI, end-systolic volume index.

Table 2 Results of ${ }^{201}$ Tl myocardial SPECT in the Acute Phase of Infarction

\begin{tabular}{lccc}
\hline \hline & $\begin{array}{c}\text { Non-Open } \\
(n=44)\end{array}$ & $\begin{array}{c}\text { Open } \\
(n=49)\end{array}$ & p value \\
\hline Defect score & $3.14 \pm 0.91$ & $3.11 \pm 0.87$ & $N S$ \\
Redistribution & $5(11)$ & $6(12)$ & $N S$ \\
Double product & $25,935 \pm 3,745$ & $24,551 \pm 2,129$ & $N S$ \\
Chest pain & $4(9)$ & $6(12)$ & $N S$ \\
\hline
\end{tabular}

Data are mean value \pm SD or number (\%).

SPECT, single photon emission computed tomography.

velocities (E/A) was then calculated. A restrictive filling pattern was diagnosed when the Dct $<150 \mathrm{~ms}^{14,15}$ As with impaired LV function, the presence of LV thrombus and aneurysm were also evaluated.

Another blood sample was taken from the peripheral vein for brain natriuretic peptide (BNP) measurement, during echocardiography. The plasma BNP concentration was measured with an immunoradiometric assay kit (Shionogi, Osaka, Japan) and expressed in $\mathrm{pg} / \mathrm{ml}$.

\section{$H R Q O L$}

HRQOL is a multi-dimensional concept reflecting a patient's own perception of the quality of their physical, psychological, and social life ${ }^{16,17}$ To evaluate these aspects we developed a self-administered questionnaire, based on the 'Duke Activity Status Index'18 and the 'Minnesota Living With Heart Failure Questionnaire'19 We simplified the overall scoring system to be 0 or 1 points awarded per question, with a higher overall score indicating better func- tion.

Statistical Analysis

Values are expressed as mean \pm SD. Comparisons between groups were performed using Student's t-test for normally-distributed continuous variables, the Mann-Whitney $\mathrm{U}$ test for non-parametric continuous variables, or the $\mathrm{X}^{2}$ test for categorical data. A p-value $<0.05$ was considered significant. Differences in survival between the 2 groups were evaluated by the Kaplan-Meier Method, and compared with the log-rank test.

\section{Results}

\section{Baseline Patient Characteristics}

In total, there were 44 patients in the Non-Open group and 49 in the Open group; 9 patients in the Open group (18\%) underwent stent implantation. Baseline patient characteristics are shown in Table 1 . There were no significant differences in age, sex, coronary risk factors or the presence of pre-MI angina between the 2 groups. The degree of heart failure measured by the Forrester classification on admission was similar in the 2 groups. In terms of infarct size, maximum CK concentrations were similar in the 2 groups.

The angiographic characteristics of the 2 groups before discharge are also shown in Table 1 . The number of diseased vessels was similar and there were also no significant differences in LV volume or systolic function at 1 month after the onset of AMI. Results of ${ }^{201} \mathrm{Tl}$ myocardial SPECT were also similar, as shown in Table 2. 
Table 3 Left Ventricular Function in the Chronic Phase of Infarction

\begin{tabular}{lccc}
\hline \hline & $\begin{array}{c}\text { Non-Open } \\
(n=29)\end{array}$ & $\begin{array}{c}\text { Open } \\
(n=37)\end{array}$ & p value \\
\hline EDVI $\left(\mathrm{ml} / \mathrm{m}^{2}\right)$ & $97.8 \pm 33.9$ & $73.6 \pm 19.8$ & 0.03 \\
$E S V I\left(\mathrm{ml} / \mathrm{m}^{2}\right)$ & $61.9 \pm 27.1$ & $44.0 \pm 15.6$ & 0.04 \\
EF $(\%)$ & $39.4 \pm 9.7$ & $46.5 \pm 10.0$ & 0.03 \\
Diastolic function & & & \\
$\quad$ E/A & $0.68 \pm 0.21$ & $0.74 \pm 0.21$ & $\mathrm{NS}$ \\
Dct $(\mathrm{ms})$ & $175.8 \pm 43.5$ & $200.5 \pm 41.8$ & $\mathrm{NS}$ \\
Restrictive pattern & $7(24)$ & $2(5)$ & 0.04 \\
LV thrombus & $4(14)$ & $0(0)$ & 0.05 \\
LV aneurysm & $7(24)$ & $0(0)$ & 0.003 \\
\hline
\end{tabular}

Data are mean value $\pm S D$ or number $(\%)$.

$E D V$, end-diastolic volume; $E S V$, end-systolic volume; $E F$, ejection fraction; E/A, ratio of early-to-late filling velocities; Dct, deceleration time of early filling.

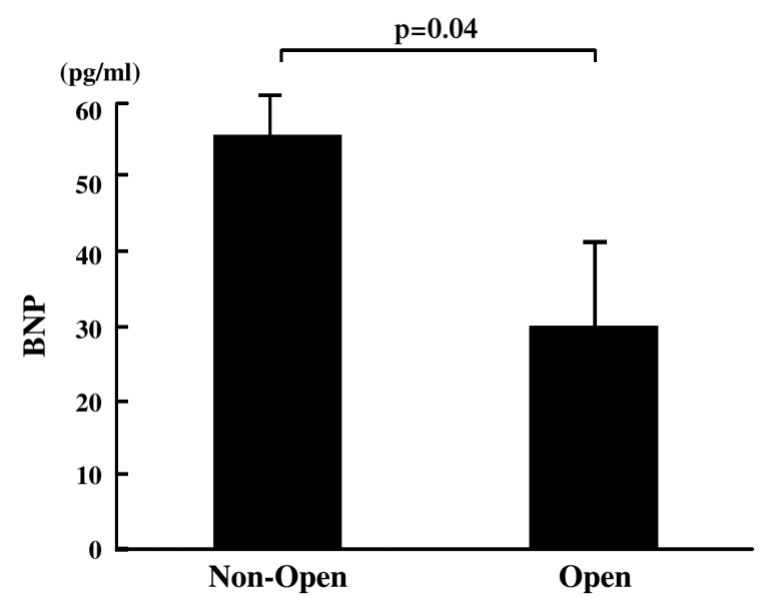

Fig 1. Plasma brain brain natriuretic peptide (BNP) concentrations were significantly higher in the Non-Open group than in the Open group $(55.8 \pm 33.1$ vs $29.9 \pm 20.0 \mathrm{pg} / \mathrm{ml}, \mathrm{p}=0.04)$.

\section{Function in the Chronic Phase}

In the present study, 29 patients (83\%) in the Non-Open group and 37 patients (79\%) in the Open group underwent 2-D echocardiography (Table 3 ). LV volume was significantly smaller and LVEF significantly better in the Open
Table 4 Cardiac Events During the 5-Year Follow-up After Infarction

\begin{tabular}{lccc}
\hline \hline & $\begin{array}{c}\text { Non-Open } \\
(n=44)\end{array}$ & $\begin{array}{c}\text { Open } \\
(n=49)\end{array}$ & p value \\
\hline Cardiac death & $7(16)$ & $1(2)$ & 0.02 \\
All death & $9(20)$ & $2(4)$ & 0.02 \\
Cardiac event & $10(23)$ & $1(2)$ & 0.01 \\
Sudden death & $6(14)$ & $0(0)$ & \\
CHF & $4(9)$ & $1(2)$ & \\
Recurrence of MI & $2(5)$ & $1(2)$ & \\
\hline
\end{tabular}

Data are number (\%).

CHF, congestive heart failure; MI, myocardial infarction. Cardiac death was defined as death from $C H F$, recurrence of MI and sudden death. Cardiac event was defined as rehospitalization for $\mathrm{CHF}$, recurrence of $\mathrm{MI}$ and cardiac death.

group than in the Non-Open group (EDVI: $73.6 \pm 19.8$ vs $97.8 \pm 33.9 \mathrm{ml} / \mathrm{m}^{2}$; ESVI: $44.0 \pm 15.6$ vs $61.9 \pm 27.1 \mathrm{ml} / \mathrm{m}^{2}$; LVEF: $46.5 \pm 10.0$ vs $39.4 \pm 9.7 \%, \mathrm{p}<0.05$, respectively). All patients in both groups had akinesis or dyskinesis in the anteroseptal region of the LV. In terms of diastolic function, the number of patients with a restrictive diastolic pattern was significantly larger in the Non-Open group (7 vs 2 , $\mathrm{p}=0.04)$. LV thrombus and aneurysm were detected only in Non-Open group patients (4 and 7 cases, respectively).

Plasma BNP concentrations were significantly higher in the Non-Open group $(55.8 \pm 33.1$ vs $29.9 \pm 20.0 \mathrm{pg} / \mathrm{ml}$, $\mathrm{p}=0.04)($ Fig 1$)$.

\section{Long-Term Follow-up}

Long-term follow-up data are shown in Table4. During the 5-year period, 7 patients $(16 \%)$ died from cardiac causes ( 1 of CHF, 2 of recurrent MI and 4 of sudden death) in the Non-Open group and 1 patient (2\%) from cardiac causes (CHF) in the Open group. Cardiac death occurred significantly more frequently in the Non-Open group $(\mathrm{p}=0.02)$. There were 2 cases $(5 \%)$ of non-cardiac death in the Non-Open group and $1(2 \%)$ in the Open group. The total incidence of death was significantly higher in the Non-Open group $(\mathrm{p}=0.02)$. Adverse cardiac events, including cardiac death, recurrence of MI and CHF, occurred significantly more frequently in the Non-Open group (10 vs 1 subjects, $p=0.01$ ). Kaplan-Meier survival curves for cardiac mortality and total mortality (Fig 2A,B) showed
A) Cardiac death

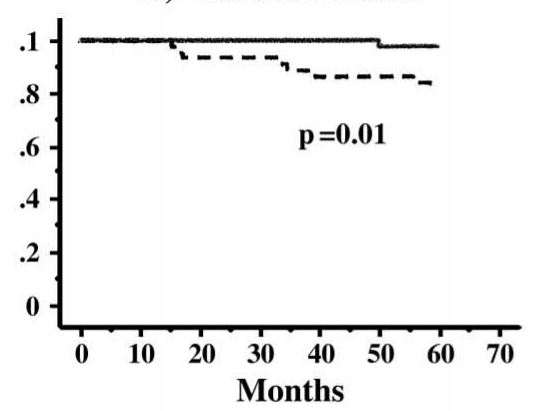

B) All death

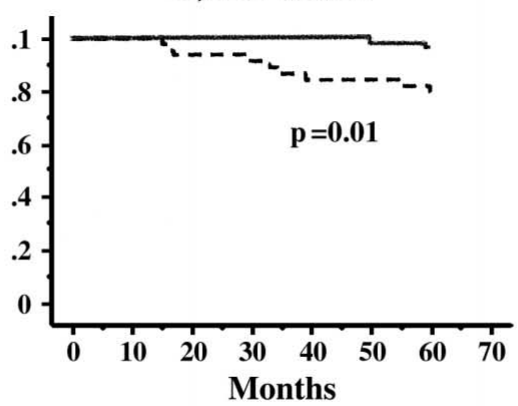

C) Event free survival

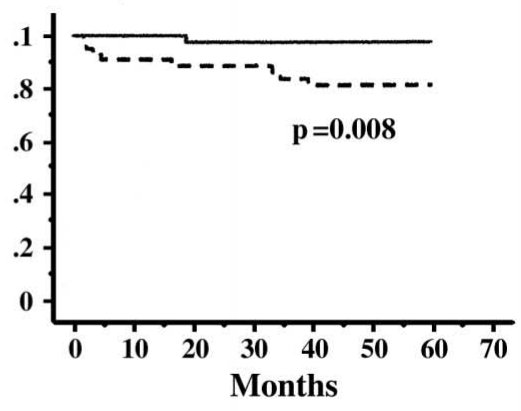

- Open, - - Non-Open

Fig 2. Kaplan-Meier survival curves for cardiac mortality (A), total mortality (B), and event free survival curves for adverse cardiac events (C) of patients in both groups. In terms of cardiac death and cardiac events, including cardiac death, non-fatal recurrence of MI and development of CHF, Open group patients had a better prognosis than Non-Open group patients during the 5-year follow-up period. 
Table 5 Cox Proportional Hazard Model for Predicting Adverse Cardiac Events

\begin{tabular}{lccc}
\hline \hline & p value & Odds ratio & $95 \%$ CI \\
\hline Age & 0.2 & 1.05 & $0.98-1.12$ \\
Male & 0.42 & 0.35 & $0.03-4.48$ \\
Totally occluded IRA & 0.01 & 34.35 & $2.21-533.98$ \\
Hypertension & 0.04 & 5.46 & $1.09-27.32$ \\
Hypercholesterolemia $(>220 \mathrm{mg} / \mathrm{dl})$ & 0.23 & 2.61 & $0.55-12.38$ \\
Diabetes mellitus & 0.9 & 1.12 & $0.22-5.72$ \\
- adrenergic receptor blocking agents & 0.83 & 0.82 & $0.13-5.00$ \\
ACEI & 0.16 & 0.19 & $0.02-1.95$ \\
Ejection fraction in acute phase & 0.35 & 1.05 & $0.95-1.17$ \\
Peak creatine kinase $(>4,000$ IU/L) & 0.12 & 3.46 & $0.72-16.61$ \\
\hline
\end{tabular}

CI, confidence interval; IRA, infarct-related artery; ACEI, angiotensin converting enzyme inhibitor.

Table 6 Health-Related Quality-of-Life Outcomes in the Chronic Phase of Infarction

\begin{tabular}{lccc}
\hline \hline & $\begin{array}{c}\text { Non-Open } \\
(n=30)\end{array}$ & $\begin{array}{c}\text { Open } \\
(n=39)\end{array}$ & p value \\
\hline QOL dimension & & & \\
Physical & $9.0 \pm 2.5$ & $10.6 \pm 2.0$ & 0.01 \\
Psychological & $7.4 \pm 2.4$ & $8.2 \pm 1.9$ & $N S$ \\
Social & $3.6 \pm 1.2$ & $4.3 \pm 0.9$ & 0.02 \\
\hline
\end{tabular}

QOL, quality-of-life.

that the Non-Open group had a significantly worse prognosis than the Open group $(\mathrm{p}=0.01)$, and the Kaplan-Meier event-free survival curves for adverse cardiac events (Fig 2C) showed that the Non-Open subjects had poor prognoses for cardiac events during the 5-year follow-up $(\mathrm{p}=0.008)$.

Further analysis of the 5-year follow-up period failed to show any significant differences between the groups in terms of medications, such as $\beta$-blocking agents or angiotensin-converting enzyme inhibitors. Cox proportional hazards analysis showed that an occluded IRA (hazard ratio $34.4, \mathrm{p}=0.01$ ) and hypertension (hazard ratio 5.5, $\mathrm{p}=0.04)$ were significantly associated with adverse cardiac events (Table 5).

\section{HRQOL Analysis}

Our HRQOL questionnaire was completed by 30 NonOpen group patients $(86 \%)$ and 39 Open group patients $(83 \%)$. Physical and social function or well-being were significantly better in the Open group $(\mathrm{p}<0.05$, respectively), but there was no significant difference for psychological well-being (Table 6).

\section{Discussion}

We believe that we are the first to report the importance of IRA patency in AMI patients known to have poor myocardial viability in the region-at-risk. The importance and efficacy of late reperfusion and maintained patency have been previously reported as dependent on inhibition of LV remodeling and not reduction in infarct size, but residual myocardial viability in the region-at-risk was not considered. Though there is no doubt that the time elapsed since the onset of symptoms and the extent of collateral flow play a part, early reperfusion and similarly, salvage of residual myocardium and recovery of stunned or hibernating myocardium may also play an important role.

\section{Effects of IRA Patency}

The largest factor in the better prognosis of the patients in the Open group compared with the Non-Open group was, we suspect, that LV remodeling was inhibited by reperfusion therapy. Cases of transmural myocardial infarction with no viable myocardium often show severe LV remodeling. ${ }^{20-22}$ However, we did not observe any significant differences between the groups in terms of acute-stage LV volume or LVEF, although in the long-term the Open group patients showed significantly smaller LV volumes and significantly better LVEF.

It has been reported that $\mathrm{LV}$ dilatation and reduced $\mathrm{LV}$ function are closely related to electrical instability 23 and that patients with associated cardiac failure and ventricular arrhythmia have a high risk of sudden death.24 In the present Non-Open group, the remarkable degree of remodeling resulted in diminished systolic and diastolic LV function, which in turn led to dysfunctional circulation and electrical instability, in themselves one cause of the significantly higher incidence of adverse cardiac events 25,26 These are also be reflected in the differences in the BNP concentrations in both groups, ${ }^{27,28}$ and the different proportions of patients showing a restrictive LV relaxation pattern.5 Generally, the degree of $\mathrm{LV}$ remodeling is determined by the relative tensile strength of the scarred collagen at the infarct site and the increased load, and if increase in wall stress does not normalize, remodeling may extend to both the border of the infarct zone and the non-infarct zone. This may be one reason for our result demonstrating that not only occluded IRA but also hypertension was associated with adverse cardiac events (Table 5). Further, we suspect that the mechanism may be based on differences in the structure of connective tissue and microvasculature; in other words, on differences in the healing process such as collagen metabolism, morphological changes in necrotic tissue, the number of residual capillaries, and the resulting inflammation at the infarct site. Although $\beta$-blocking agents and angiotensin-converting enzyme inhibitors inhibit remodeling and improve neurohormonal conditions, $20,27-30$ there were no differences in the medical regimens of the 2 groups and therefore we do not consider that these agents had a great influence. The primary mechanism of the benefit to be gained from IRA patency is inhibition of LV remodeling, and residual myocardial viability is not a major factor in this. In fact, almost all patients in both groups had akinesis in the anteroseptal region, and no improvement was observed during the follow-up period. Furthermore, as well as LV function, the advantages of the patent IRA were seen in HRQOL outcomes. 


\section{Study Limitations}

First and foremost, this was neither a randomized nor a prospective analysis. However, in the patient population drawn from 2 institutions with different treatment strategies, we found no significant differences in acute-stage LVEF, LVEDVI or LVESVI, nor, excluding those cases that suffered mortality within 1 year of onset, did we observe any great difference between the groups in the severity of MI. This would imply that selection bias should be lower than would be the case for a simple retrospective study of a single hospital. Second, the study population was highly selective and relatively small, so our results may not be generally applicable to the post-MI population. Third is our use of exercise ${ }^{201} \mathrm{Tl}$ myocardial SPECT with re-injection at 1 month after the onset of AMI for determining the degree of myocardial viability. The possibility exists that we missed some residual viable myocardium at the time of patient selection. The current 'gold standard' for assessing myocardial viability is positron emission tomography (PET). However the assessment of myocardial viability is a complex issue, and of the several studies that have compared PET and ${ }^{201} \mathrm{Tl}$ myocardial SPECT with re-injection, ${ }^{11,12,31-34}$ some have reported that there is a possibility that ${ }^{201} \mathrm{Tl}$ myocardial SPECT with re-injection underestimates the extent of tissue viability, although it has $\geq 80 \%$ of the diagnostic accuracy of PET 33,34 Furthermore, the wall motion of myocardial segments that do not have new fill-in on ${ }^{201} \mathrm{Tl}$ myocardial SPECT with re-injection rarely improves after bypass surgery!1 ${ }^{11}$ addition, the cost-benefit ratio of PET for management of CAD has not been defined. We therefore believe that our assessment is essentially accurate and the fact that we saw no improvement in wall motion in the present patients suggests that also. Fourth, we used CAG at 1 month after the onset of AMI to determine the occluded IRA in the Non-Open group, which means we did not assess spontaneous reperfusion of the IRA. Finally, to evaluate $\mathrm{LV}$ function in the chronic phase, we performed 2-D echocardiography not LVG, meaning that serial changes in LV volume and function in each patient were not evaluated.

\section{Clinical Implications}

Our results suggest beneficial effects of late reperfusion and patent IRA on the long-term prognosis of anterior AMI patients with poor viable myocardium in the region-at-risk. Therefore, in the modern stent era where coronary patency can easily and reliably be secured, reperfusion therapy through PCI is beneficial not only in the acute phase but also in the sub-acute to chronic phase, even in patients with little or no viable myocardium in the region-at-risk. The importance and significance of reperfusing the IRA, at least in cases of anterior AMI, may therefore go beyond the traditional goal of acute myocardial salvage, and may continue to be beneficial even after the clinical 'completion' of infarction.

The 'open-vessel theory', which is not dependent on the recovery of viable myocardium, suggests an important role for PCI beyond the acute phase of anterior AMI. Further examination and extension of the indications for PCI may provide still increased benefits for anterior AMI patients, even when there is poor viability in the region of the myocardium at risk.

\section{References}

1. Gruppo Italiano per lo Studio della Streptochinasi nell' infarto miocardico (GISSI). Long-term effects of intravenous thrombolysis in acute myocardial infarction: Final report of GISSI study. Lancet 1987; 2: 871-874.

2. The TIMI Study Group. The Thrombolysis in Myocardial Infarction (TIMI) trial. $N$ Engl J Med 1985; 312: 932-936.

3. Topol EJ. Coronary angioplasty for acute myocardial infarction. Ann Intern Med 1988; 109: 970-980.

4. Zijlstra F, de Boer MJ, Hoorntje JCA, Reiffers S, Reiber JH, Suryapranata H. A comparison of immediate coronary angioplasty with intravenous streptokinase in acute myocardial infarction. $N$ Engl J Med 1993; 328: 680-684.

5. Kim CB, Braunwald E. Potential benefits of late reperfusion of infarcted myocardium: The open artery hypothesis. Circulation 1993; 88: $2426-2436$.

6. Horie H, Takashi M, Minai K, Izumi M, Takaoka A, Nozawa M, et al. Long-term beneficial effect of late reperfusion for acute anterior myocardial infarction with percutaneous transluminal coronary angioplasty. Circulation 1998; 98: 2377-2382.

7. Sabri MN, DiSciascio G, Cowley MJ, Goudreau E, Warner M, Kohli RS, et al. Immediate and long-term results of delayed recanalization of occluded acute myocardial infarction-related arteries using coronary angioplasty. Am J Cardiol 1992; 69: 575-578.

8. Bauters C, Delomez M, Van Belle E, McFadden E, Lablanche JM, Bertrand ME. Angiographically documented late reocclusion after successful coronary angioplasty of an infarct-related lesion is a powerful predictor of long-term mortality. Circulation 1999; 99: $2243-2250$.

9. Hirayama A, Adachi T, Asada S, Mishima M, Nanto S, Kusuoka H, et al. Late reperfusion for acute myocardial infarction limits the dilatation of left ventricle without the reduction of infarct size. Circulation 1993; 88: 2565-2574.

10. Kennedy JW, Trenholme SE, Kasser IS. Left ventricular volume and mass from single-plane cineangiogram: A comparison of anteroposterior and right anterior oblique methods. Am Heart J 1970; 80: $343-$ 352.

11. Tamaki N, Ohtani H, Yamashita K, Magata Y, Yonekura Y, Nohara $\mathrm{R}$, et al. Metabolic activity in the areas of new fill-in after thallium201 reinjection: Comparison with positron emission tomography using fluorine-18-deoxyglucose. J Nucl Med 1991; 32: 673-678.

12. Bonow RO, Dilsizian V, Cuocolo A, Bacharach SL. Identification of viable myocardium in patients with chronic coronary artery disease and left ventricular dysfunction: Comparison of thallium scintigraphy with reinjection and PET imaging with $18 \mathrm{~F}$-fluorodeoxyglucose. Circulation 1991; 83: 26-37.

13. Steven CP, Imaging Guidelines for Nuclear Cardiology Procedures. J Nucl Cardiol 1999; 6: G47-G84.

14. Klein AL, Hatle LK, Taliercio CP, Oh JK, Kyle RA, Gertz MA, et al. Prognostic significance of Doppler measures of diastolic function in cardiac amyloidosis: A Doppler echocardiography study. Circulation 1991; 83: 808-816.

15. Pozzoli M, Traversi E, Cioffi G, Stenner R, Sanarico M, Tavazzi L. Loading manipulations improved the prognostic value of Doppler evaluation of mitral flow in patients with chronic heart failure. Circulation 1997; 95: $1222-1230$

16. Gorkin L, Norvell NK, Rosen RC, Charles E, Shumaker SA, McIntyre $\mathrm{KM}$, et al. Assessment of quality of life as observed from the baseline data of the Studies Of Left Ventricular Dysfunction (SOLVD) trial quality-of-life substudy. Am J Cardiol 1993; 71: 1069-1073.

17. Coyne KS, Lundergan CF, Boyle D, Greenhouse SW, Draoui YC, Walker P, et al. Relationship of infarct artery patency and left ventricular ejection fraction to health-related quality of life after myocardial infarction: The GUSTO-1 Angiographic Study Experience. Circulation 2000; 102: 1245-1251.

18. Hlatky MA, Boineau MA, Higginbotham MB, Lee KL, Mark DB, Califf RM, et al. A brief self-administered questionnaire to determine functional capacity (the Duke Activity Status Index). Am J Cardiol 1989; 64: 651-654.

19. Rector TS, Kubo SH, Cohn JN. Patients' self-assessment of their congestive heart failure. Part 2: Content, reliability and validity of a new measure, the Minnesota Living With Heart Failure Questionnaire. Heart Fail 1987; Oct/Nov: 198-209.

20. Pfeffer MA, Braunwald E. Ventricular remodeling after myocardial infarction: Experimental observations and clinical implications. Circulation 1990; 81: 1161-1172.

21. Warren SE, Royal HD, Markis JE, Grossman W, McKay RG. Time course of left ventricular dilatation after myocardial infarction: Influence of infarct-related artery and success of coronary thrombolysis. 
J Am Coll Cardiol 1988; 11: 12-19.

22. Seals AA, Pratt CM, Mahmarian JJ, Tadros S, Kleiman N, Roberts $\mathrm{R}$, et al. Relation of left ventricular dilatation during acute myocardial infarction to systolic performance, diastolic dysfunction, infarct size and location. Am J Cardiol 1988; 61: 224-229.

23. Hohnloser SH, Frank P, Klingenheben T, Zabel M, Just H. Open infarct artery, late potentials, and other prognostic factors in patients after myocardial infarction in the thrombolytic era: A prospective trial. Circulation 1994; 90: 1747-1756.

24. Gaudron P, Kugler I, Hu K, Bauer W, Eilles C, Ertl G. Time course of cardiac structural, functional and electrical changes in asymptomatic patients after myocardial infarction: Their inter-relation and prognostic impact. J Am Coll Cardiol 2001; 38: 33-40.

25. Grossman W. Diastolic dysfunction in congestive heart failure. $N$ Engl J Med 1991; 325: 1557-1564.

26. Litwin SE, Katz SE, Morgan JP, Douglas PS. Serial echocardiographic assessment of left ventricular geometry and function after large myocardial infarction in rat. Circulation 1994; 89: 345-354.

27. Maeda K, Tsutamoto T, Wada A, Hisanaga T, Kinoshita M. Plasma brain natriuretic peptide as a biochemical marker of high left ventricular end-diastolic pressure in patients with symptomatic left ventricular dysfunction. Am Heart J 1998; 135: 825-832.

28. Takagi, S, Sakuragi S, Baba T, Takaki, H, Aihara N, Yasumura Y, et al. Predictors of left ventricular remodeling in patients with acute myocardial infarction participating in cardiac rehabilitation. Circ $J$ 2004; 68: 214-219.

29. Yang YJ, Tang YD, Ruan YM, Zhang P, Zhou YW, Wang PH, et al. Comparative effects of carvedilol and losartan alone and in combination for preventing left ventricular remodeling after acute myocardial infarction in rats. Circ $J$ 2003; 67: 159-162.

30. Izutani S, Yoshiyama M, Omura T, Yoshida K, Nakamura Y, Kim S, et al. Nipradilol can prevent left ventricular systolic and diastolic dysfunction after myocardial infarction in rats. Circ J 2002; 66: 289-293.

31. Sutton MG, Sharpe N. Left ventricular remodeling after myocardial infarction: Pathophysiology and therapy. Circulation 2000; 101: 2981-2988.

32. Niemeyer MG, Kuijper AF, Meeder JG, Cramer MJ, Cleophas AJ, van der Wall EE. Comparison of thallium scintigraphy and positron emission tomography. Angiology 1997; 48: 843-853.

33. Ogiu N, Nakai K, Hiramori K. Thallium-201 reinjection images can identify the viable and necrotic myocardium similarly to metabolic imaging with glucose loading 18F-fluorodeoxyglucose (18FDG)PET. Ann Nucl Med 1994; 8: 171-176.

34. Ragosta M, Beller GA. The noninvasive assessment of myocardial viability. Clin Cardiol 1993; 16: 531-538. 